\title{
Current practices in family planning: a population based study
}

\author{
Asmita Kaundal, Rohini Sehgal, Garima Kachhawa, Sunesh Kumar, \\ Alka Kriplani, P. Vanamail*
}

Department of Obstetrics and Gynecology, AIIMS, New Delhi, India

Received: 29 March 2019

Accepted: 14 May 2019

\section{*Correspondence:}

Dr. P. Vanamail,

E-mail: pvanamail@gmail.com

Copyright: (C) the author(s), publisher and licensee Medip Academy. This is an open-access article distributed under the terms of the Creative Commons Attribution Non-Commercial License, which permits unrestricted non-commercial use, distribution, and reproduction in any medium, provided the original work is properly cited.

\section{ABSTRACT}

Background: To study the knowledge, current practices of family planning methods and acceptance post motivation. Methods: Cross-sectional study conducted at family planning OPD of AIIMS, New Delhi, India. A total of 1516 couples who came for MTP at any gestation couple were enquired about knowledge, currently used contraceptive method and reason for abortion. Couple was counseled and allowed to choose contraceptive method using cafeteria approach. Mean values of continuous data were tested using t-test/ANOVA. Categorial data were compared using chi-square/ Fischers exact test.

Results: Mean \pm SD age of the women was $28.89 \pm 5.21$ years with $9.98 \pm 4.56$ weeks POG. Around $81 \%$ of women had one or more living children with $62.67 \%$ women with at least one abortion previously. Majority used male condoms $(42.10 \%)$ followed by natural method $(21.01 \%)$, Cu-T $(3.80 \%)$, OCPs $(1.65 \%)$, injectable $(0.30 \%)$, I-pill $(0.24 \%)$. Awareness was maximum for male condoms, Cu-T, OCPs, female sterilization (100\%) and least for female condoms $(20 \%)$ and LNG-IUS $(8.46 \%)$. Contraceptive failure $(68.90 \%)$, congenital abnormality in the fetus $(22.40 \%)$, maternal disease $(5.90 \%)$, rape $(1.60 \%)$, completed family $(0.80 \%)$ and not using any method $(0.30 \%)$ were the reasons of abortion. Majority of abortions were in first trimester (70\%). Post-motivation around $69.30 \%$ of the couples accepted some form of contraception. Female sterilization (32.50\%) method accepted by the couples as compares to temporary methods $(36.70 \%)$ such as $\mathrm{Cu}-\mathrm{T}$, OCPs, Injectables etc.

Conclusions: Despite of awareness the family planning programme is unsuccessful largely due to inappropriate attitude. Behavioral modification and communication goes a long way to slove the problem.

Keywords: Awareness, Behavioral modification, Contraception, Family planning methods, Post-motivation

\section{INTRODUCTION}

India launched its first National Family Planning Programme in 1952. The main objective was to stabilize its rapidly growing population to preserve its exhausting resources. Over the years several different strategies like target-free approach, contraceptive specific incentive, family planning camps, cafeteria approach, has been adopted. From initial clinical approach to current Reproductive and child health programme there has been lot of efforts and transformations. ${ }^{1-3}$ To legalize abortions, prevent unplanned births, unsafe abortions and related complications Medical Termination (MTP) Act was implemented in the year 1971. ${ }^{4}$ Emergency contraception (I-pill) was included in the National family planning and welfare programme in the year 2002 and were made available over the counter in 2005 to prevent unintended pregnancies. ${ }^{5}$ Despite of 67 years of National Family Planning Programme and 47 years of MTP Act currently India is the second most populated country in world after China with around $17.74 \%$ of the world's total population. Abortion still remains one of the major 
contributors of maternal mortality accounting for $8 \%$ of the maternal deaths in India. ${ }^{6-7}$

There has been tremendous advancement in the field of contraception and family planning. Three spacing (Oral contraceptive pills, Intrauterine devices, male condoms) and two limiting (male and female sterilization) methods are provided free under the National programme in all Government sectors. Many other with different compositions (hormonal and non-hormonal) and route of administration (oral, injectable, rings, patches, LNG-IUS) are being made available in both private and Government sector to address the concern of side effects, preference and suitability of one route of administration over the other. Lot of efforts has been put to spread awareness about the need of safe sexual practices, need for family planning methods and their availability, still the compliance to family planning services remain poor. Hence this study was carried out to see the awareness and practices about the various family planning methods, various family planning practices, reasons for abortions in the present scenario and acceptance for contraceptive methods post motivation.

\section{METHODS}

Family planning programme is routinely carried out in the Family Planning OPD of Obstetrics and Gynaecology, All India Institute of Medical Sciences, New Delhi. Activities such as counseling of couple for various family planning measures (Temporary and permanent), carrying out MTP and providing appropriate and desired family planning services are implemented.

This is a cross-sectional study where 1516 women who opted for MTP during the period March 2017 to December 2018 were included. A detailed history about women's demographic profile, present and past medical and surgical history and obstetric history are recorded. Ethical clearance was taken from the Ethical Committee of Institute. For these women information was collected about their knowledge on various contraceptive methods, previously used methods and reason for current abortion. Gestational age of the present pregnancy was calculated from the last menstural period and confirmed by ultrasound. Couple was counseled pre and post abortion about the available family planning services. Couple was free to choose a method based upon cafeteria approach.

\section{Statistical analysis}

Data analysis was carried out using IBM SPSS version 23.0 software. Continuous variables were tested for normality assumption using Kolmogorov-Smirnov test. For normally distributed data descriptive statistics such as mean, standard deviation and range values were calculated. Mean values were compared using Student's t-test/ANOVA as appropriate. Categorical data were expressed as frequency and percent values. Frequency data were compared using Chi-sqaure /Fishers Exact test as appropriate. A two-sided probability of $\mathrm{P}<0.05$ was considered for statistical significance.

\section{RESULTS}

Total 1516 couples who came for medical termination of pregnancy and gave consent to participate in study were included in the study. Mean \pm SD age of the women was $28.89 \pm 5.21$ years with $74.60 \%$ women between the age of 20-25 years while $3.23 \%$ were below 19 years and $10.29 \%$ above 35 years of age. Mean \pm SD period of gestation at the time of abortion was $9.98 \pm 4.65$ weeks. Majority of the women were married (96.4\%). Around $20.4 \%$ women were illiterate, $32.2 \%$ educated till primary level, $13.2 \%$ till secondary, $34.2 \%$ were graduate and above. Majority of women were housewives $(82.5 \%)$ followed by $13.6 \%$ were working in either government or private sector and $3.9 \%$ were students. Around $81 \%$ of women had one or more living children with mean \pm SD duration of last child birth being $38.27 \pm 38.46$ months while $19 \%$ were pregnant for the first time. Almost $62.67 \%$ women have had undergone abortion previously.

Table 1: Demographic profile of the study population.

\begin{tabular}{|ll|}
\hline Population (n=1516) & $28.89 \pm 5.21$ \\
\hline Mean age of the women (years) & $32.86 \pm 5.19$ \\
\hline Mean age of the men (years) & $2.78 \pm 1.26$ \\
\hline Gravida & $1.77 \pm 1.26$ \\
\hline Parity & $1.77 \pm 1.26$ \\
\hline Live issues & $38.27 \pm 38.46$ \\
\hline Duration of last child birth(months) & $1.661 \pm 2.5$ \\
\hline Abortions & $9.9833 \pm 4.56$ \\
\hline $\begin{array}{l}\text { Mean gestation age at abortion } \\
\text { (weeks) }\end{array}$ & $96.4 \%$ \\
\hline Married & $3.6 \%$ \\
\hline Unmarried & \\
\hline Education & $20.4 \%$ \\
\hline Illiterate & $32.2 \%$ \\
\hline Primary & $13.2 \%$ \\
\hline Secondary & $23.0 \%$ \\
\hline Graduate & $11.1 \%$ \\
\hline Postgraduate & \\
\hline Occupation & $82.0 \%$ \\
\hline Housewives & $9.4 \%$ \\
\hline Government Jobs & $4.3 \%$ \\
\hline Private jobs & $3.9 \%$ \\
\hline Students & \\
\hline
\end{tabular}

Around $30.9 \%$ of couple did not use any contraceptive method previously, $21.01 \%$ practiced natural method of contraception including safe period and coitus interruptus. Out of those using modern methods majority used male condoms $(42.10 \%)$, followed by $\mathrm{Cu}-\mathrm{T}$ $(3.80 \%)$, Oral contraceptive pills $(1.65 \%)$ and injectable $(0.30 \%)$. Around $0.24 \%$ had used emergency contraceptive (I-pill) in place of regular method. 


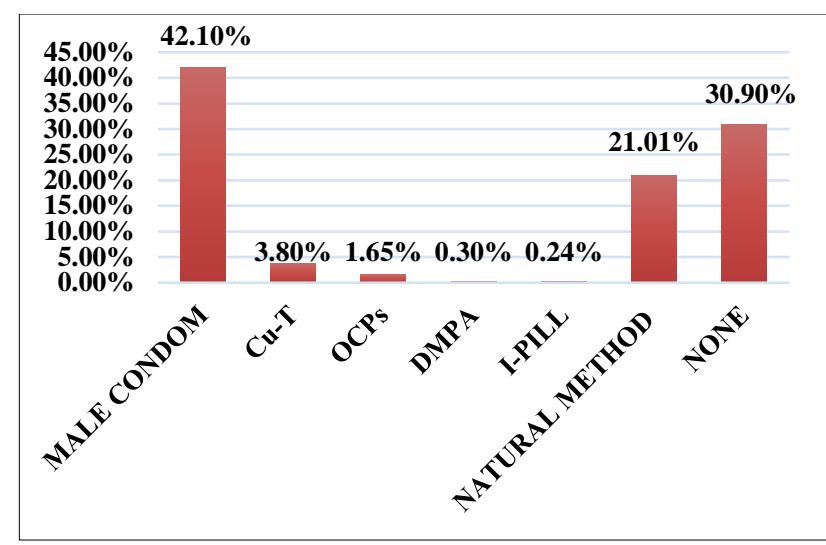

Figure 1: Contraceptive used previously.

On assessment of awareness about the contraceptive methods it was seen that almost all couple knew about at least one method of contraception. Awareness was maximum for male condoms, $\mathrm{Cu}-\mathrm{T}$, OCPs, Female sterilization (100\%) followed by male sterilization $(98.26 \%)$, emergency contraceptive $(72.65 \%)$, injectables $(45.60 \%)$, rings and patches $(23 \%)$. Knowledge was least for female condoms (20\%) and LNG-IUS (8.46\%).

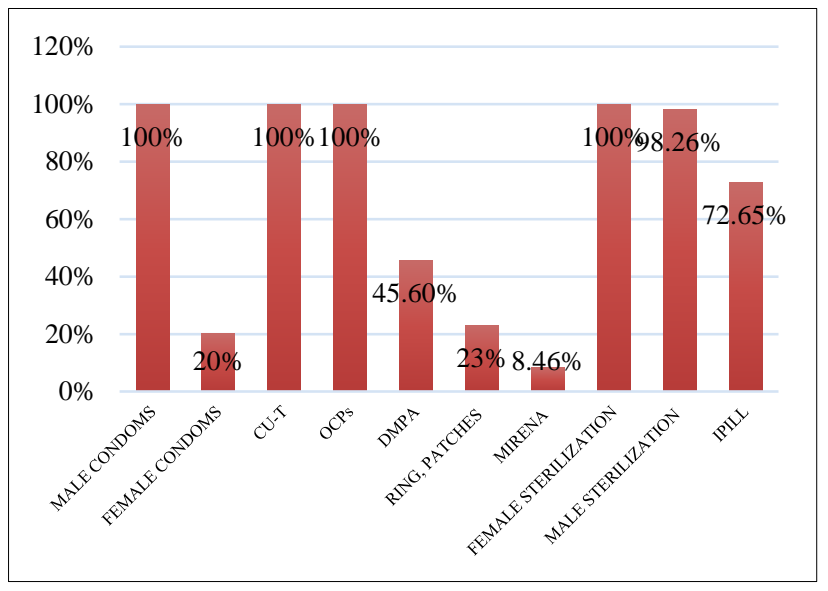

Figure 2: Awareness about different family planning methods.
Most common reason for the unplanned pregnancy was contraceptive failure $(68.90 \%)$, followed by congenital abnormality in the fetus $(22.40 \%)$, maternal disease $(5.90 \%)$, rape $(1.60 \%)$, completed family $(0.80 \%)$ and not using any method $(0.30 \%)$.

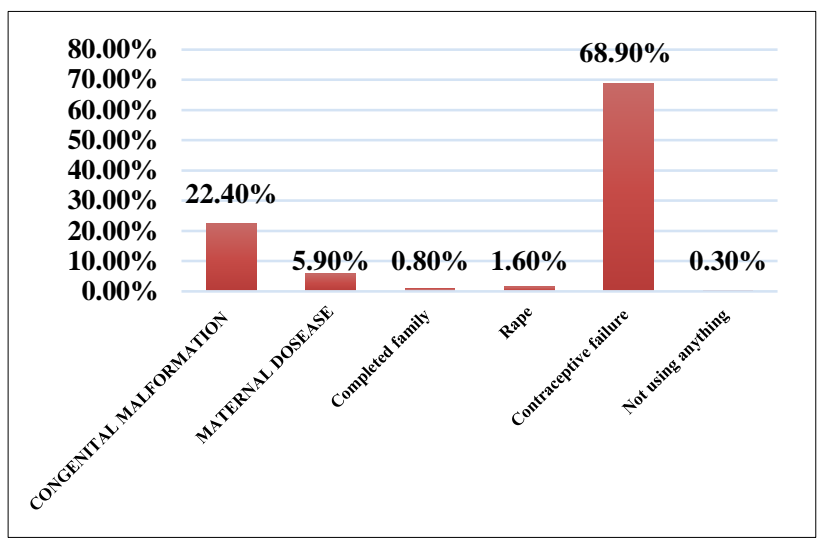

Figure 3: Reasons for unplanned pregnancy.

Out of all the abortions $70 \%$ were first trimester and around $30 \%$ were done in second trimester. Most common reason for the first trimester abortion was contraceptive failure (87\%) and congenital abnormalities in the babies for second trimester abortions $(69.50 \%)$.

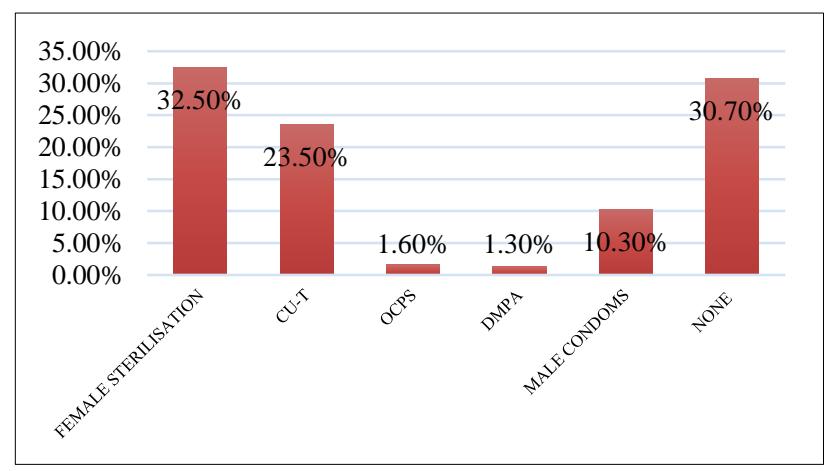

Figure 4: Contraceptive opted post motivation.

Table 2: Trimester wise distribution of reasons for abortion.

\begin{tabular}{|lllllll|} 
Reasons & $\begin{array}{l}\text { Congenital } \\
\text { abnormality } \\
\text { in the baby }\end{array}$ & $\begin{array}{l}\text { Maternal } \\
\text { disease }\end{array}$ & $\begin{array}{l}\text { Completed } \\
\text { family }\end{array}$ & $\begin{array}{l}\text { Contraception } \\
\text { failure }\end{array}$ & $\begin{array}{l}\text { Rape } \\
\text { Using } \\
\text { anything Not }\end{array}$ \\
\hline First trimester & $2.60 \%$ & $8.10 \%$ & $0.90 \%$ & $87.0 \%$ & $0.90 \%$ & $0.40 \%$ \\
\hline Second trimester & $69.50 \%$ & $0.70 \%$ & $0.40 \%$ & $26.0 \%$ & $3.40 \%$ & $0.0 \%$ \\
\hline
\end{tabular}

Post motivation around $69.3 \%$ of the couples accepted some form of contraception while $30.7 \%$ still did not opt for any method. Out of all those who opted for the contraception maximum opted for female sterilization
$(32.50 \%)$ as the couple has already completed family and did not wish to have more children, followed by $\mathrm{Cu}-\mathrm{T}$ $(23.50 \%)$, male condoms $(10.30 \%)$, OCPs $(1.60 \%)$ and DMPA $(1.30 \%)$ for those who wanted to preserve their fertility. 
Out of those who did not opt for any contraception $60.50 \%$ were desirous of pregnancy, $7.50 \%$ of women with maternal disease opted to abstain but not use any contraception during the period of their treatment, $7.30 \%$ told had occasional exposure and did not require any regular method despite of counselling, 5.40\% had accidental pregnancy due to rape, $0.60 \%$ expressed that they did not want to use any measure and $18.70 \%$ did not give any specific reason.

The results were correlated with the age of the women and it was found that the younger women (<19years) were more reluctant to opt contraception while as the age advances the trend was to opt for permanent method of contraception than the temporary methods.

When the data was analyzed to any association between the education and occupation of the couple and the contraception opted post motivation it was seen that no significant difference was found between the various groups.

\section{DISCUSSION}

Though there has been a lot of effort by Government to improve quality and acceptance of the family planning services yet replacement levels of fertility has not been achieved. Around $13 \%$ of the married women still has unmet need for contraception either for spacing or limiting birth. There has been increase in unplanned pregnancies and abortions in the country. ${ }^{8}$

In our study we found that $3.23 \%$ women were less than 20 years (teen pregnancies) National Family Health Survey (NHS-4) also states that around $8 \%$ of the women in India have either delivered or are pregnant with their first child by the age of 15-19 years. ${ }^{9}$ At such a young age women is neither physically nor emotionally ready for pregnancy, abortion or childbirth increasing the burden of maternal morbidity and mortality. ${ }^{10-14}$

Around $30 \%$ of the all the abortions were done in second trimester when it is relatively not safe to terminate pregnancy. Most common reason for seeking MTP in second trimester was congenital abnormalities in the baby $(69.50 \%)$. In the present scenario such high rate of abortions due to congenital abnormalities can be justified due to the advanced technologies to detect such abnormalities which are not compatible with life and are unavoidable.

Out of all the teen pregnancies $61.22 \%$ of the women presented in second trimester probably because of inexperience in recognizing the signs of pregnancy earlier, fear of exclusion from the family and society, hesitation in seeking medical advice due to fear of disclosure, lack of knowledge about medicolegal aspect related to abortion and confidentiality of medical information in the country. ${ }^{15-16}$ NHS-4 states that $11 \%$ of women and $1 \%$ of men initiate sexual activity at the age of 15 years and at the age of 20 years nearly $59 \%$ of women and $55 \%$ of men are already sexually active implying that $59 \%$ of the women are already at risk of teen pregnancy. To address the issue of teen pregnancies and abortions sex education and contraceptive awareness should be a part of school curriculum at much earlier ages so that children are aware of the safe sex practices, contraceptives and consequences of early pregnancy and abortions long before their first sexual contact.

Despite of the knowledge and awareness about any one of the modern methods of contraceptive method $30.9 \%$ were not using any method and those who were using were either not using them properly or were using inconsistently leading to high rate of contraceptive failure $(68.90 \%)$. Out of all the MTPs $59.56 \%$ abortions were opted by those who already had 2 or more living children but were not using any effective method of contraception. Similar trend was seen by Moore AM et al. where authors found that due to various reasons like lack of proper communication and planning between the couple, lack of acceptance to the available methods of contraception and associating use of contraceptive with decreased sexual pleasure, many couple prefer abortion over contraception to avoid pregnancy. ${ }^{17}$

Though a variety of modern contraceptive methods are available at affordable price/free in both private and public sectors still the most common method used is male condoms which was in contrary to the observation in previous various studies and National health survey which states that the consumption of male contraception is low as there is lack of male participation and responsibility in sexual and reproductive health matters. ${ }^{18}$ Other spacing methods like $\mathrm{Cu}-\mathrm{T}$, OCPs, injectables were less used because of the fear of side effects of the hormonal contraception and IUCDs translating to failure of national programmes to provide successful spacing methods to postpone first child birth or spacing between subsequent pregnancies. ${ }^{19}$ Emergency contraception was introduced in the national family planning and welfare programme in 2002. Even after 17 years its usage remains less due to lack of awareness about its proper use. In our study only $0.24 \%$ of women had used emergency contraception as a backup measure to avoid unplanned pregnancy.

Pre and post abortion counselling was done for the couples who came for MTPs and were found to be eligible for family planning services and couple were free to choose any of the methods using cafeteria approach. It was seen out of $69.3 \%$ couple who accepted contraception majority $32.50 \%$ accepted female sterilization followed by $\mathrm{Cu}-\mathrm{T}$, Male condoms, OCPs and Injectables. The data was found to be in accordance with the National Health Family Survey-4 (NHS-4) which states female sterilization is the most common method (36\%) used to limit birth. Infact studies have shown that majority of women $(77 \%)$ who got ligated had never used any other method of contraception in their lifetime. It was 
a method most commonly used even by married adolescent women and a large number of women were ligated even before the age of 26 years. ${ }^{20,21}$ In our study the number of women who had never used any method and opted for sterilization was slightly lower (34.48\%) and the mean age at sterilization was $30.33 \pm 3.24$ years may be because of proper patient selection at the time of offering sterilization. No male sterilizations were opted as against $0.3 \%$ according to NHS-4 though the method is much more simpler than female sterilization because of cultural practices and attitude towards family planning methods and services. ${ }^{22}$ Therefore, male participation in the birth limiting methods is still negligible.

While assessing the reasons for various methods opted, permanent method of female sterilization a terminal method was opted for an obvious reason, completed family and no desire for future children. Spacing methods were used by those who wanted to either space pregnancies or wanted to preserve fertility. Around $30.7 \%$ (47\% accordingly to NHS-4) couple who did not accept any contraception majority wanted to conceive $(60.50 \%)$. Other reasons were due to maternal diseases so willing to abstain till the period of treatment $(7.50 \%)$, occasional exposure $(7.30 \%)$, rape $(5.40 \%)$, did not want to use $(0.60 \%)$ and no specific reason $(18.70 \%)$.

While relating the contraceptive methods opted post motivation, we found that younger women were more reluctant to use any contraception despite of current MTP (84\%) and those who accepted most of them opted for male condoms (4\%) and very few opted $\mathrm{Cu}-\mathrm{T}(2 \%)$. The reason could be because out of all the pregnancies in age group below 20 years $51.02 \%$ pregnancies were because of non-consensual sex. Remaining $10.2 \%$ of women were unmarried and had occasional exposure and hence did not want to use any regular method of contraception.

We tried to find relation between education and occupation with the contraceptive practices and contraceptive opted but no significant relation was found implying towards inappropriate attitude towards family planning than lack of knowledge and awareness. Therefore, behavioural modification through proper communications goes a long way in the successful implementation of various family planning programmes. ${ }^{23-24}$

\section{CONCLUSION}

Even though variety of family planning methods are available at affordable prices in all private sectors and free in all government institutes population control is still a major challenge even when the awareness and knowledge seems to be adequate because of inappropriate attitude towards family planning. So an effort towards change of such attitude and family planning practices is required to stabilize population, prevent unplanned births, abortions and complications associated with it. Clinician should use every opportunity to assess the need for contraception, counsel the couple and help them choose what suits them the best. Contraception should be an essential part of school curriculum so that the adolescents are sensitized from very initial stage even before they are exposed to the risk of pregnancy.

\section{Funding: No funding sources}

Conflict of interest: None declared

Ethical approval: The study was approved by the Institutional Ethics Committee

\section{REFERENCES}

1. National Population Policy: Yojana. 1983;26;27(12):55-6.

2. Sangwan N, Maru RM. The target-free approach: An overview: J Health Manag. 1999;1(1);71-96.

3. Chaurasia AR, Singh R. 40 years of planned family planning efforts in India. Available at; https://iussp.org/en/event/17/programme/paper/5465.

4. The medical termination of pregnancy Act, 1971 (Act No. 34 of 1971). Available at; http://tcw.nic.in/Acts/MTP-Act-1971.pdf.

5. Mittal S. Introduction of emergency contraception in India; J Indian Med Assoc. 2006;104(9)499-502, 504-5.

6. Say L, Chou D, Gemmill A. Global caused of maternal death: a WHO systematic analysis. Lancet Global Heatlth. 2014;2:e323-33.

7. Montgomery AL, Ram U, Kumar R, Jha P. For the million death study collaborators maternal mortality in India: causes and healthcare service use based on a nationally representative survey. PLoS ONE. 2014;9(1):e83331.

8. Singh S, Shekhar C, Acharya R. Moore AM, Stillman M. The incidence of abortion and unintended pregnancies in India, 2015. Lancet Global Health. 2018;6(1):e111-20.

9. India, Mumbai: IIPS; December 2017. International Institute for Population Sciences (IIPS) and Macro International. National Family Health Survey (NFHS-4). 2015-16.

10. Nove A, Matthews Z, Neal S, Camacho AV. Maternal mortality in adolescent compared with women of other ages: evidence from 144 countries. Lancet Glob Health. 2014;2:e155-164.

11. Kassa GM, Arowojolu AO, Odukogbe AA, Yalew AW. Prevalence and determinants of adolescent pregnancy in Africa : A systematic review and metaanalysis. Reproductive Health. 2018;15(1):195.

12. WHO. Adolescent pregnancy-Unmet needs and undone deeds: a review of the literature and programmes,

2007. https://apps.who.int/iris/bitstream/handle/10665/4370 2/9789241595650_eng.pdf?sequence $=1$.

13. Peter M. World Health Organization. Pregnant adolescents : delivering on global promises of hope, 2006. World Health Organization. http://www.who.int/iris/handle/10665/43368. 
14. Sedgh G, Finer LB, Bankole A, Eilers MA, Singh S. Adolescent pregnancy, birth and abortion rates across countries: Levels and trends. J Adolescent Health. 2015;56(2):223-0.

15. Reynolds HW, Wong EL, Tucker H. Adolescents' use of maternal and child health services in developing countries. Int Persp Sexual Health Reprod Health. 2006;32(1):6-16.

16. Ganatra B, Hirve S. Induced abortion among adolescent women in rural Maharashtra, India. Reproductive Health Matters. 2002;10:76-85.

17. Moore AM, Singh S, Bankole A. Do women and men consider abortion as an alternative to contraception in united states? An exploratory study. Global Public health, An Int J Res Policy Pract. 2011;6(1):S25-37.

18. Pachauri S. Priority strategies for India's family planning programme. Indian $\mathrm{J}$ Med Res. 2014;140(1):S137-S148.

19. Pachauri S. Expanding contraceptive choice in India: Issues and evidence. J Fam Welfare. 2004;50:13-25.

20. India, Mumbai: IIPS; 2007. International Institute for Population Sciences (IIPS) and Macro International. National Family Health Survey (NFHS-3), 2005-06.
21. Mumbai: IIPS; 2010. International Institute for Population Sciences, Population Council. Youth in India: Situation and needs 2006-2007. Available at; https://www.popcouncil.org/uploads/pdfs/2010PGY_ YouthInIndiaReport.pdf.

22. Pachauri S. Special Article. Male involvement in reproductive health care. J Indian Med Assoc. 2001;99:138-41.

23. Bhatnagar I, Khan ME, Hazra A. New Delhi: Population Council; 2011. Increasing acceptance of spacing methods in rural Bihar: Implications for behaviour change communication. Policy Brief No. 5 .

24. Darmstadt GL, Tarigopula UK. Behavior change communication as an intervention to improve family health outcomes. J Fam Welfare. 2010;56:1-8.

Cite this article as: Kaundal A, Sehgal R, Kachhawa G, Kumar S, Kriplani A, Vanamail P. Current practices in family planning: a population based study. Int J Reprod Contracept Obstet Gynecol 2019;8:2372-7. 